\title{
Spatially resolved measurements of nitrogen dioxide in an urban environment using concurrent multi-axis differential optical absorption spectroscopy
}

\author{
R. J. Leigh ${ }^{1}$, G. K. Corlett ${ }^{1}$, U. Frieß ${ }^{1, *}$, and P. S. Monks ${ }^{1}$ \\ ${ }^{1}$ University of Leicester, Leicester, UK \\ * now at: University of Heidelberg, Heidelberg, Germany
}

Received: 17 November 2006 - Published in Atmos. Chem. Phys. Discuss.: 5 December 2006

Revised: 13 August 2007 - Accepted: 21 August 2007 - Published: 18 September 2007

\begin{abstract}
A novel system using the technique of concurrent multi-axis differential optical absorption spectroscopy system has been developed and applied to the measurement of nitrogen dioxide in an urban environment. Using five fixed telescopes, slant columns of nitrogen dioxide, ozone, water vapour, and the oxygen dimer, $\mathrm{O}_{4}$, are simultaneously retrieved in five vertically separated viewing directions. The application of this remote sensing technique in the urban environment is explored. Through the application of several simplifying assumptions a tropospheric concentration of $\mathrm{NO}_{2}$ is derived and compared with an urban background in-situ chemiluminescence detector. Trends derived from remote sensing and in-situ techniques show agreement to within 15 to $40 \%$ depending on conditions. Owing to the high time resolution of the measurements, the ability to image and quantify plumes within the urban environment is demonstrated. The CMAX-DOAS measurements provide a useful measure of overall $\mathrm{NO}_{2}$ concentrations on a city-wide scale.
\end{abstract}

\section{Introduction}

Public exposure to nitrogen dioxide $\left(\mathrm{NO}_{2}\right)$ in the urban environment is a health concern, a public policy concern and the subject of several national and international directives on air quality. At present monitoring/measurement uses networks of spatially sparse in-situ monitors coupled to emission inventories and empirical models to estimate $\mathrm{NO}_{2}$ concentrations and exceedences of air quality standards. Considerable spatial inhomogeneity in the dynamics, meteorology and chemistry of the urban atmosphere leaves such tech-

Correspondence to: P. S. Monks

(P.S.Monks@leicester.ac.uk) niques open to significant uncertainties unless datasets are available against which they can be rigorously validated. The urban atmosphere therefore presents a substantial measurement and modeling challenge.

Zenith-viewing UV/Visible scattered light differential optical absorption spectroscopy (DOAS) has been used over a number of decades for the retrieval of atmospheric concentrations of traces species including $\mathrm{O}_{3}, \mathrm{NO}_{2}, \mathrm{BrO}, \mathrm{OClO}, \mathrm{IO}$, $\mathrm{HCHO}$ and $\mathrm{O}_{4}$. (e.g. Noxon (1975); Noxon et al. (1979); Solomon et al. (1987); Johnston and McKenzie (1989); Van Roozendael et al. (1994); Aliwell et al. (2002); Frieß et al. (2001); Wittrock et al. (2000); Tornkvist et al. (2002)) In recent years, systems incorporating off-axis (non-zenith) measurements have been developed (e.g. Sanders, 1996; Miller et al., 1997; Hönninger et al., 2004b,c; Bobrowski et al., 2003; Leser et al., 2003; Wittrock et al., 2004; Heckel et al., 2005; Sinreich et al., 2006) Off-axis techniques exploit the improved sensitivity of non-zenith measurements to tropospheric trace-gas concentrations owing to the enhanced tropospheric path length of collected scattered light. Through the incorporation of multiple off-axis viewing geometries, information on the profile and spatial distribution of trace gases can be retrieved.

The DOAS technique can be used to measure absorption by trace species throughout the path length of scattered solar radiation (Platt, 1994) As a general rule the stratospheric path length is modulated by changing solar zenith angle while the tropospheric path length is dominated by changes in instrument viewing geometry (Hönninger et al., 2004a) Tropospheric sensitivity is minimised in the zenith view, as photons are generally scattered in the lower stratosphere and upper troposphere and therefore take a vertical path straight through the boundary layer. Off-axis viewing angles with elevations less than 20 degrees above the horizon

Published by Copernicus Publications on behalf of the European Geosciences Union. 
Mean Annual Concentrations for 2001 Interpolated From Modelled Points. Monitoring Station Locations Shown

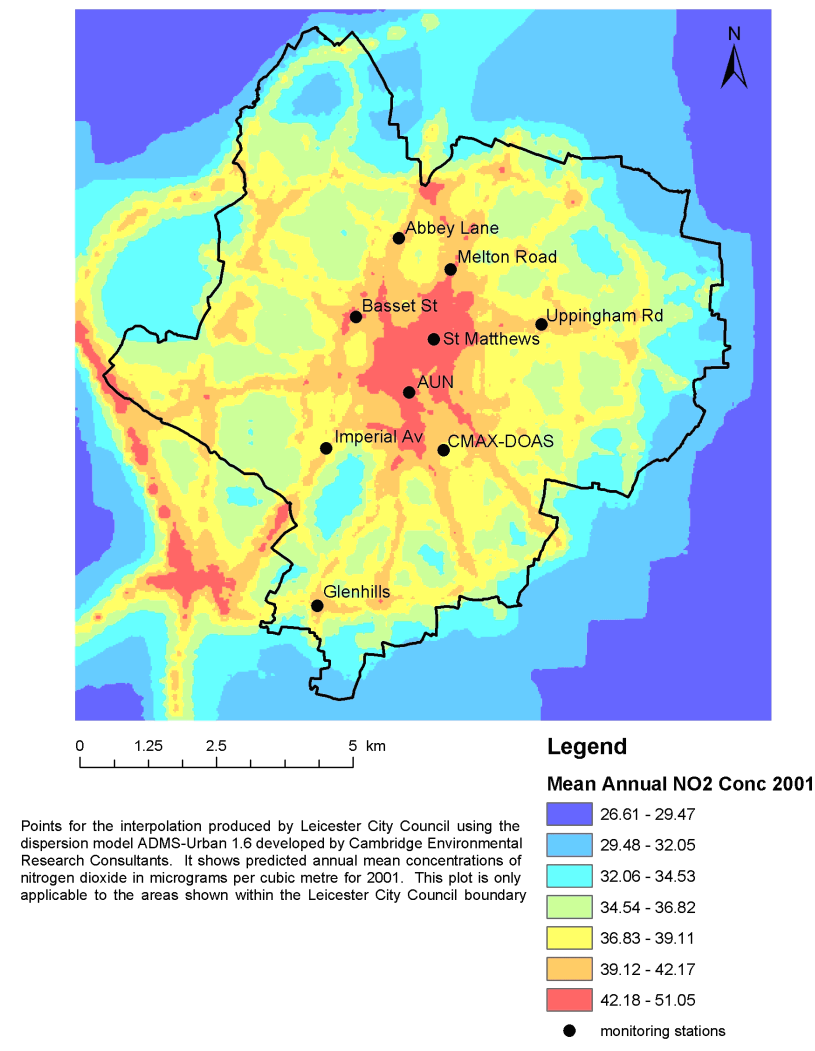

Fig. 1. Modeled $\mathrm{NO}_{2}$ concentrations in the Leicester Area, produced by the ADMS model, using assimilated data from the automated monitoring stations marked on the map. The location of the CMAX-DOAS instrument is shown.

have much greater sensitivity to the tropospheric concentrations of trace species as the last scattering point for the photons received by the instrument is much lower in the atmosphere and is horizontally displaced from the instrument, giving a longer tropospheric absorption path (see for example Hönninger et al., 2004b).

Much work to date has concentrated on the measurement of background concentrations of $\mathrm{NO}_{2}$ and halogen species in remote rural or polar regions (Frieß et al., 2001; Wittrock et al., 2004). For such measurements the temporal resolution of the instrument is not a primary concern as concentrations are expected to change over timescales of hours or days rather than minutes. As such, consecutive measurements from different viewing geometries are appropriate with a total scan of all viewing axes taking several minutes. However, for analysis of rapidly varying and spatially inhomogeneous concentrations of trace species in the boundary layer, simultaneous measurement of all viewing angles is highly desirable. This paper describes the application of a concurrent multi-axis DOAS (CMAX-DOAS) system that measures five or more viewing geometries simultaneously and has been tested in urban conditions to measure the concentration and time evolution of boundary-layer nitrogen dioxide $\left(\mathrm{NO}_{2}\right)$.

\section{Experimental}

The CMAX-DOAS instrument was installed on the roof of the Space Research Centre at the University of Leicester $\left(52.62^{\circ} \mathrm{N}, 1.12^{\circ} \mathrm{W}\right)$ at the end of 2003 . A full description of the CMAX-DOAS instrument can be found in Leigh et al. (2006). Briefly, the instrument comprises of five telescopes, fixed in a northerly direction at 2, 5, 10, 15 and 90 degrees (zenith) elevation. The telescopes are connected via fibre-optic cables to an Oriel MS257 imaging spectrometer, which concurrently images spectra from all viewing geometries onto a Marconi 48-20 CCD. Spectra retrieved from these images are analysed using the DOAS technique (Platt, 1994) to derive differential slant column densities of $\mathrm{NO}_{2}$, ozone, $\mathrm{H}_{2} \mathrm{O}$ and the oxygen dimer $\mathrm{O}_{4}$. Errors on retrieved differential slant columns of $\mathrm{NO}_{2}$ are approximately $2 \%$ for analysis on a single fibre, and 5\% error on analysis involving spectra from one fibre and a reference spectrum from a different fibre (Leigh et al., 2006; Leigh, 2006). Detection limits calculated using the RMS fit residual following the technique of Stutz and Platt (1996) are $1.4 \times 10^{15} \mathrm{~mol} \mathrm{~cm}^{-2}$ for a single fibre, and $3.2 \times 10^{15}, 4.2 \times 10^{15}$ and $4.7 \times 10^{15} \mathrm{~mol} \mathrm{~cm}^{-2}$ for the 15,10 and 5 degree views respectively when using a zenith reference spectrum.

A clear view to the North was available, unobstructed by tall buildings and trees. The location of the installation in respect to the town centre and main traffic routes is shown in Fig. 1. Also shown in Fig. 1 are modeled mean annual $\mathrm{NO}_{2}$ concentrations in the Leicester Area, and the location of 8 automated monitoring stations, operated by the local City Council. The northerly-pointing off-axis views sampled air masses over the main urban city centre in Leicester. The heterogeneity of the air-masses sampled by the different viewing directions limited the profiling capabilities of the CMAXDOAS instrument using existing techniques. However, the concurrent nature of the multi-axis measurements can provide simultaneous analysis of different air-masses.

\section{Results}

The instrument was operated on 124 days during 2004 with a 2 min temporal resolution. An example set of daily data from 20th May 2004 is shown in Fig. 2. These data demonstrate the ability of the CMAX-DOAS system to concurrently measure $\mathrm{NO}_{2}, \mathrm{O}_{4}, \mathrm{O}_{3}$ and $\mathrm{H}_{2} \mathrm{O}$. For analysis, the reference spectrum from the zenith view was used as reference for the off-axis views, providing maximum spatial information.

The stratospheric dominance of the ozone signal can be seen in the lack of dependence of measurement on viewing geometry, with a differential slant column purely dependent 

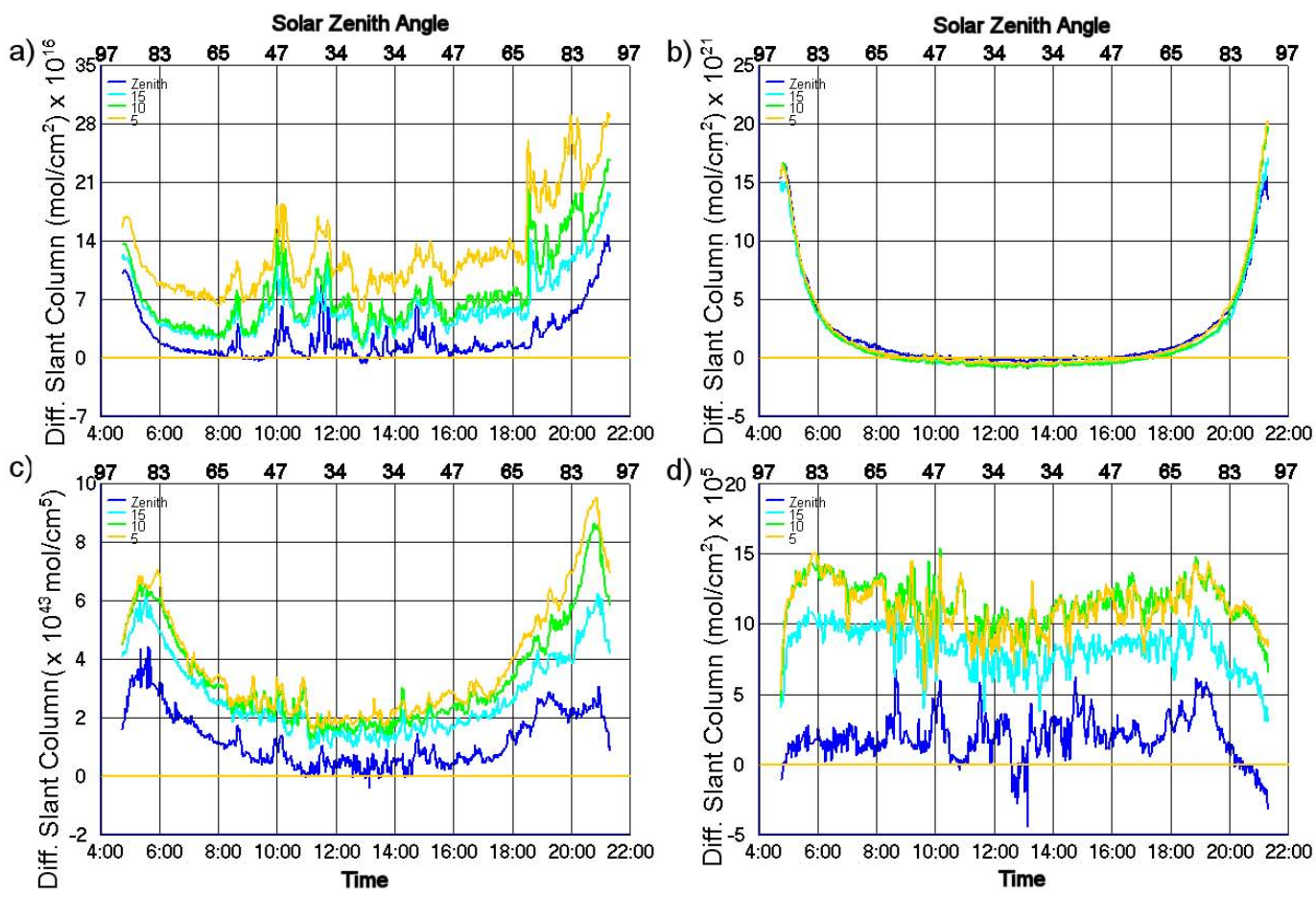

Fig. 2. Slant columns for all retrieved absorbers from Thursday 20th May 2004 for all viewing axes. Panels are: (a) $\mathrm{NO}_{2}$, (b) $\mathrm{O}_{3}$, (c) $\mathrm{O}_{4}$, (d) $\mathrm{H}_{2} \mathrm{O}$.

upon solar zenith angle. The $\mathrm{NO}_{2}$ and $\mathrm{O}_{4}$ differential slant columns demonstrate both tropospheric and stratospheric signals while the $\mathrm{H}_{2} \mathrm{O}$ signal as expected is dominated by tropospheric signal. The constant and known profile of $\mathrm{O}_{4}$ permits information to be obtained on the abundance of cloud or haze on a given day (Wagner et al., 2004). Clouds and haze influence photon path lengths by altering atmospheric scattering properties. While thick clouds can increase path lengths through increased scattering between and within clouds, thin cloud or haze will reduce path lengths in offaxis measurements, as scattering of photons is more likely to occur near the CMAX-DOAS instrument. Therefore, on this day, the $\mathrm{O}_{4}$ differential slant columns indicate light nonuniform cloud as shown by the non-smooth curves, and the proximity of measurements from different axes. More cloud and haze effects are evident in the morning than the evening where dusk measurements almost resemble clear-sky conditions.

The $\mathrm{NO}_{2}$ differential slant column contains information on stratospheric $\mathrm{NO}_{2}$, contained in the solar zenith angle dependence of measurements at dawn and dusk, particularly in the zenith measurement which is least influenced by tropospheric concentrations. The diurnal increase in stratospheric $\mathrm{NO}_{2}$ can be seen in the increased SZA dependence in the dusk measurements over dawn. In addition, tropospheric concentrations are clearly evident in the separation of the offaxis signals, and short temporal features. Path length changes indicated in $\mathrm{O}_{4}$ measurements will also influence $\mathrm{NO}_{2}$ measurements. For example, in Fig. 2 cloudy features appearing in the $\mathrm{O}_{4}$ columns at 10 a.m. and 3 p.m. also appear as enhancements in the $\mathrm{NO}_{2}$ differential slant columns.

Differential slant column data were produced for all 124 days on which measurements were taken. Short and long-term analysis was therefore possible to investigate individual features and establish diurnal, weekly, seasonal and annual concentrations.

\subsection{Comparisons with in situ $\mathrm{NO}_{2}$ monitors}

In order to build up a long time series of tropospheric $\mathrm{NO}_{2}$ concentrations, a simple algorithm was developed to convert the CMAX-DOAS measurements into volume mixing ratios. This algorithm relies on the following assumptions:

1. The absorption by $\mathrm{NO}_{2}$ outside of the polluted boundary layer is the same from both the zenith and off-axis viewing geometries.

2. Clouds when present are a uniform layer above the polluted boundary layer PBL, and scattering causing increased absorption is identical in both the zenith and off-axis views.

3. The aerosol profile is essentially a box profile of 0.1 optical depth from the surface up to $1500 \mathrm{~m}$. 
4. The tropospheric component of the $\mathrm{NO}_{2}$ profile is a box profile from the surface to $1500 \mathrm{~m}$.

The validity of assumptions 1 and 2 are a function of the ratio of the concentrations of $\mathrm{NO}_{2}$ within and beyond the urban boundary layer as well as the scattering properties of the atmosphere. With a cleaner background air mass, or higher concentrations of $\mathrm{NO}_{2}$ in the urban boundary layer, the influence of differing absorption properties outside the area to be studied is reduced. The accuracy of assumptions 3 and 4 is dependent on the nature of the temporal and spatial variability in aerosol loading and $\mathrm{NO}_{2}$ profile. The $1500 \mathrm{~m}$ profile depth is a first approximation of the polluted boundary layer (PBL) height in an urban environment. The PBL height changes diurnally, and seasonally and $1500 \mathrm{~m}$ is used as a realistic approximation for an urban environment during the day (Menut et al., 1999; Eresmaa et al., 2006).

The aerosol and $\mathrm{NO}_{2}$ profiles from assumptions 3 and 4 were used as inputs into the radiative transfer model SCIATRAN (Rozanov et al., 2000, 2001) to produce air mass factors for $\mathrm{NO}_{2}$ for each viewing angle. These air mass factors for 70 degrees solar zenith angle were 2.4, 4.7, 5.6 and 6.5 for the zenith, 15, 10 and 5 degree angles respectively. The difference between these air mass factors is a result of the increased path length through the lowermost atmosphere for the 5, 10 and 15 degree views. The stratospheric component of each airmass factor is approximately equal (Hönninger et al., 2004a). Therefore, by subtracting the zenith air mass factor, the stratospheric component is removed from each, along with a proportion of the tropospheric component.

Comparable tropospheric differential slant column measurements are produced by using a zenith reference spectrum to analyse each of the non-zenith views, and then subtracting the concurrent zenith differential slant column measurement for each reading. This removes the stratospheric signal, and leaves a residual tropospheric differential slant column, $\left(\mathrm{SC}_{\mathrm{RTrop}}^{\text {non-zen }}\right)$.

$S C_{\mathrm{RTrop}}^{\mathrm{non}-\mathrm{zen}}=N_{\text {Trop }} \bullet\left(A M F^{\text {non-zen }}-A M F^{\text {zen }}\right)$

Therefore, by dividing $\mathrm{SC}_{\mathrm{RTrop}}^{\text {non-zen }}$ by $2.3,3.2$ and 4.1 for the 15,10 and 5 degree views respectively, a tropospheric

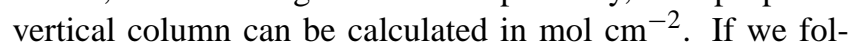
low assumption 4 that our $\mathrm{NO}_{2}$ is distributed uniformally throughout our $1500 \mathrm{~m}$ assumed PBL, then an absolute concentration in $\mathrm{mol} \mathrm{cm}^{-3}$ can be achieved through division by $1.5 \times 10^{5}$, and a concentration in $\mu \mathrm{g} \mathrm{m}^{-3}$ retrieved by a further division by $1.29 \times 10^{10}$ (the conversion factor from $\mathrm{mol}^{-3}$ to $\mu \mathrm{g} \mathrm{m}^{-3}$ ). Both the radiative transfer model, and the calculation of $\mathrm{SC}_{\mathrm{RTrop}}^{\text {non-zen }}$ assume that the $\mathrm{NO}_{2}$ is in wellmixed layers above the instrument. In an urban PBL this is unrealistic, as will be demonstrated later, but is a necessary assumption for this step.

Derived concentrations for the 3 primary non-zenith viewing angles are shown in Fig. 3. The absolute concentrations derived using Eq. (1) are linearly dependent upon the assumed PBL height, which in reality changes both diurnally and seasonally. One would therefore expect a relative under-estimation from the CMAX-DOAS measurements in the mornings, and during the winter months. Work is ongoing to determine the magnitude of this effect. Nevertheless, diurnal, weekly and seasonal trends are still clearly represented in both the CMAX-DOAS and in situ data shown in Fig. 3. The in situ monitor selected for this comparison exercise is located between two large buildings at the location marked "AUN" in Fig. 1. This location is selected to obtain an urban background without dominant influences from any single road, junction or industrial emission.

The data in Fig. 3 demonstrate the level of agreement between the CMAX-DOAS measurements and those from a chemiluminescence detector over a periods during 2004. The weekly cycle is clearly evident in the upper panels, with the lowest concentrations from both instruments measured on Sundays. Given the difference in spatial sampling of the two measurements, the degree of agreement is significant. The instrument was reconfigured several times during 2004, which would contribute to varying calculated errors over the year. Other contributory factors will be the varying height of the PBL and atmospheric scattering properties including cloud prevalence and aerosol loading. The PBL height can vary from 500 to $2000 \mathrm{~m}$ depending upon conditions. The error in derived concentration using a PBL height of 1500 $\mathrm{m}$ could therefore be as much as $+33 \%$ or $-66 \%$. The correlation between the most sensitive $5^{\circ}$ view and the in situ data during these periods gives a measure of the accuracy of the technique in determining trends in $\mathrm{NO}_{2}$ concentration. As the CMAX-DOAS instrument is measuring a more dispersed airmass, the derived concentrations are significantly lower than the in situ measurements. The CMAX-DOAS data is therefore multiplied by a factor of three to render it directly comparable to the in situ figures for an error analysis on the measured trends. The figure of $5 \mu \mathrm{g} \mathrm{m}^{-3}$ from the week in May can be taken as an error margin during optimal operation. Whereas $10.9 \mu \mathrm{g} \mathrm{m}^{-3}$ is a more accurate assessment of the performance of the technique over the whole measurement period. The potential influence of clouds was investigated through the flagging of data in which there was at least $3 \times 10^{42} \mathrm{~mol} \mathrm{~cm}^{-5}$ separation between the $\mathrm{O}_{4}$ differential slant column measurement from the $15^{\circ}$ view and the $10^{\circ}$ view and a further $3 \times 10^{42} \mathrm{~mol} \mathrm{~cm}^{-5}$ separation between the $10^{\circ}$ view and the $5^{\circ}$ view. This subset of data (approximately $12 \%$ of the total dataset) gave a broad representation of relatively clear-sky conditions. The improvement in the agreement with the in situ data using this subset was less than $10 \%$ (to $4.6 \mu \mathrm{g} \mathrm{m}^{-3}$ during May, and $10.1 \mu \mathrm{g} \mathrm{m}^{-3}$ for the complete dataset). Within the accuracies of this technique, this result can be interpreted as confirmation of the general validity of the assumption that in the polluted urban environment absorption by $\mathrm{NO}_{2}$ in the PBL dominates the retrieved tropospheric signal. However, there is a small influence on measurements owing to increased scattering due 

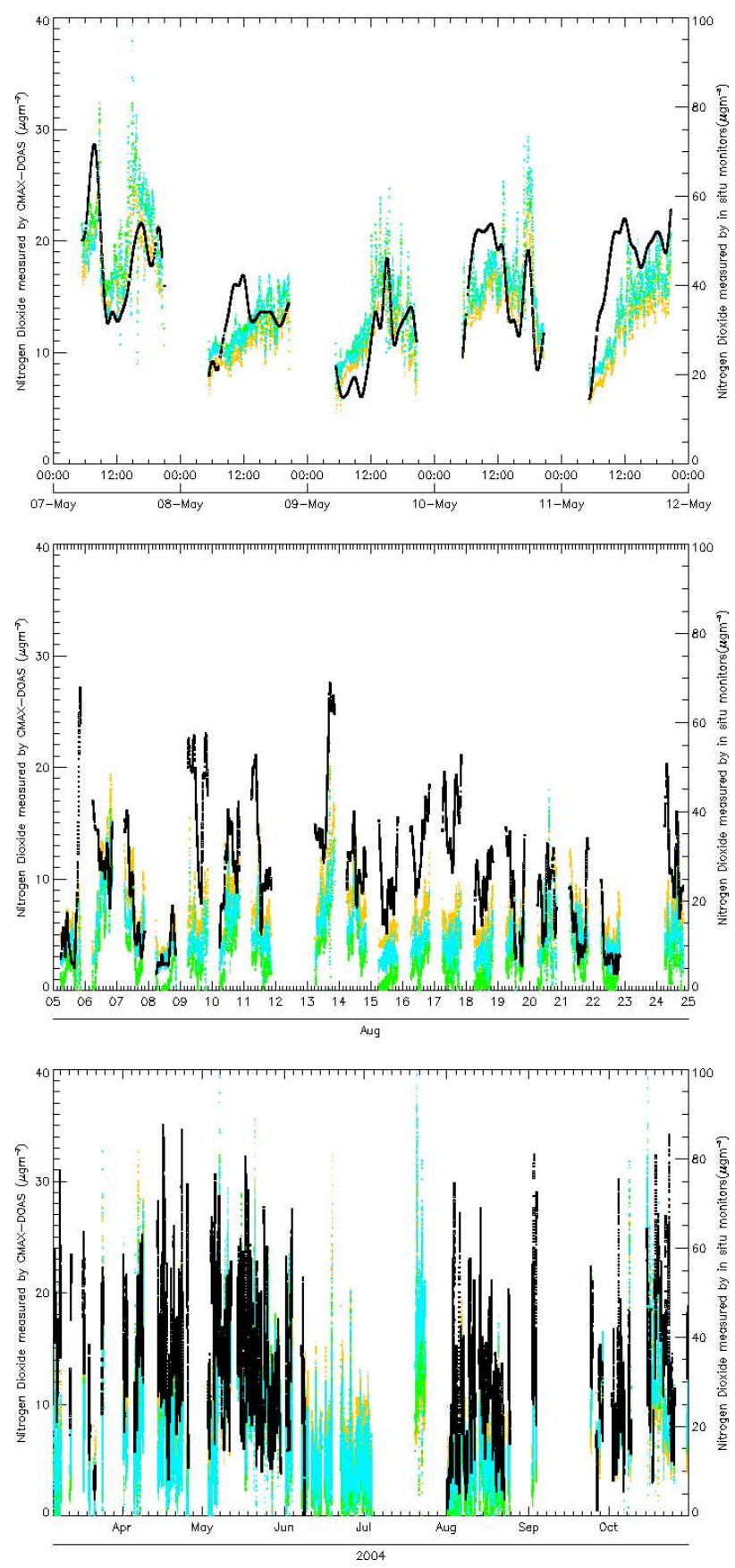

Fig. 3. Derived tropospheric concentrations from the 5 (yellow), 10 (green) and 15 (blue) degree viewing angles of the CMAX-DOAS instrument, and data from the in-situ chemiluminesence monitor (black) for a week in May, 3 weeks in August, and the whole of 2004. RMS differences between these three datasets (after a factor of 3 has been applied to the CMAX-DOAS data) are $5.5 \mu \mathrm{g} \mathrm{m}^{-3}$ / $15 \%$ (May) $10.1 \mu \mathrm{g} \mathrm{m}^{-3} / 40 \%$ (August) and $10.9 \mu \mathrm{g} \mathrm{m}^{-3} / 33.6 \%$ (2004)

to clouds.

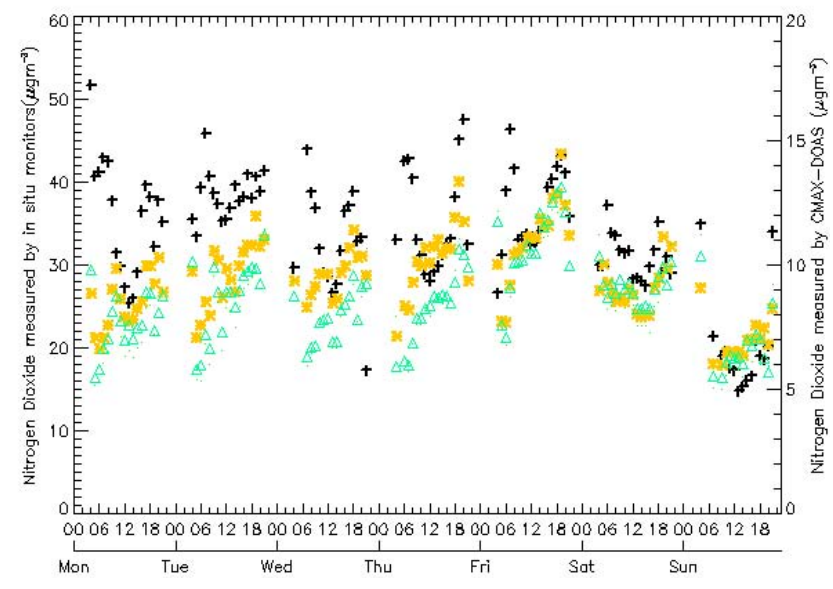

Fig. 4. Average concentrations of $\mathrm{NO}_{2}$ in Leicester for each hour of the week as measured by the 5,10 and 15 degree angles of the CMAX-DOAS instrument and by in situ monitors during 2004.

The reproduction of the weekly trend, and the identification of short-term features is a significant piece of evidence that the CMAX-DOAS method is able to measure the $\mathrm{NO}_{2}$ concentration in the polluted urban boundary layer, directly measuring the times and relative intensities of emission events. From Friday 7th May to Tuesday 11th May, morning and evening rush hours can be seen on week days, with lower concentrations and different diurnal patterns evident during Saturday and Sunday. However, complex metereology and the different sampling volumes, as well as errors introduced by the assumptions made here result in average errors of $15 \%$ during optimal operation (based on a mean concentration of $38.9 \mu \mathrm{g} \mathrm{m}^{-3}$ ) and $33.6 \%$ over the entire measurement period (based on a mean concentration of $32.4 \mu \mathrm{g} \mathrm{m}^{-3}$ ).

From all the data collected it is possible to derive average concentrations for a given time on a given day of the week. Figure 4 shows 1-hour binned average concentrations from all available CMAX-DOAS and in situ data in 2004. The normal diurnal and weekly anthropogenic cycles are evident in these data.

Wind data combined with the CMAX-DOAS dataset gives information on the influence of prevailing wind conditions on urban air quality, and the causes of differences between measurements by the in-situ chemiluminescence monitor and the CMAX-DOAS instrument. Figure 5 shows data from the 5,10 and 15 degree views for all periods in which CMAXDOAS and chemiluminescence measurements were available concurrently (a total of 1412 hourly data points). The influence of wind direction on average $\mathrm{NO}_{2}$ concentrations can be clearly seen with winds from the East of the city leading to the lowest measurements from both techniques. The influence of the CMAX-DOAS viewing geometry can be seen in data during southerly winds. A southerly wind 


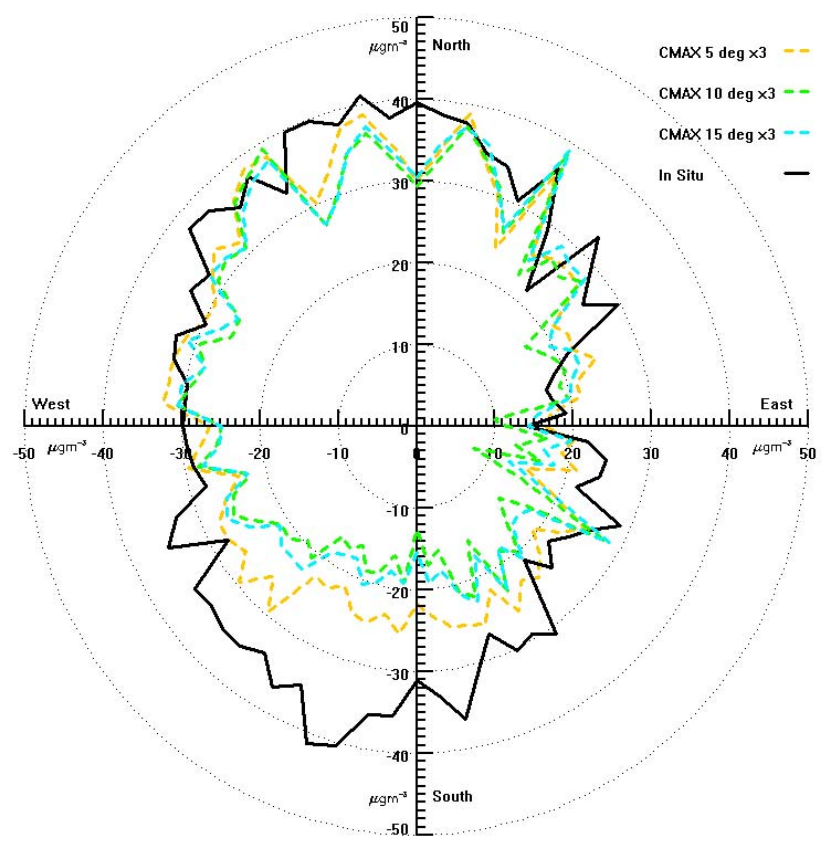

Fig. 5. Annual average $\mathrm{NO}_{2}$ concentrations in $\mu \mathrm{g} \mathrm{m}^{-3}$ for a given wind direction from the 15,10 and 5 degree views of the CMAXDOAS instrument, and the in-situ chemiluminesence monitor. The CMAX-DOAS measurements have been multiplied by a factor of three to utilise the same axes.

will naturally disperse city centre emissions to the north of the city, away from the CMAX-DOAS instrument. As the CMAX-DOAS instrument's viewing geometry is inclined, polluted air masses are sampled later and at a higher altitude in southerly winds, or may possibly not be sampled at all. This is the reason for the distinct divergence between CMAX-DOAS measurements and chemiluminescence data in southerly wind directions. However, the good correlation on all axes in all other wind conditions suggests that the use of a CMAX-DOAS system with multiple viewing geometries from a single measurement location south of a city centre can provide reliable information on concentrations of $\mathrm{NO}_{2}$ in the air mass directly over the city.

\subsection{Observations of unmixed $\mathrm{NO}_{2}$ airmasses}

Analysis of a rare clear-sky morning period on 17th January 2004 is used to demonstrate the potential of the CMAXDOAS instrument to retrieve information on the optical depth of the PBL and the dynamical progression of individual air masses. Retrieval of aerosol parameters with multi-axis DOAS has been demonstrated previously (Wagner et al., 2004; Frieß et al., 2006). The full technique of Frieß et al. (2006) could not be used in this instance as absolute radiances were not available in this work due to the sampling and retrieval software used on the CCD. Therefore a simpler
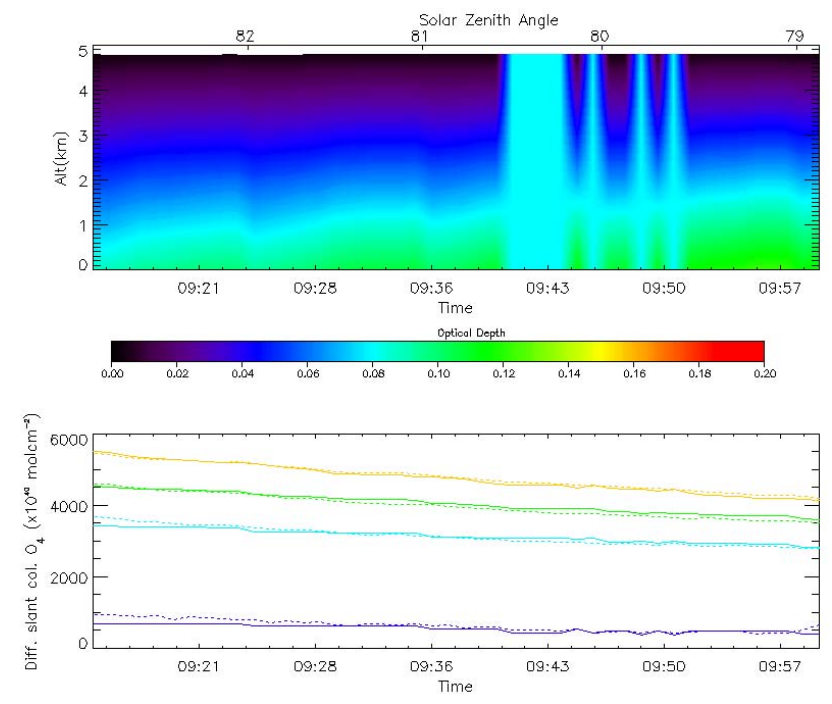

Fig. 6. Aerosol optical depth retrieval (upper panel) and measured (dotted lines) and modelled (solid lines) $\mathrm{O}_{4}$ columns from 17th January 2004

look-up table approach was used. Using SCIATRAN, differential slant columns of $\mathrm{O}_{4}$ were modelled with a variety of aerosol profiles and optical depths. Using a least-squared fit, the profile that most closely matched the observed differential $\mathrm{O}_{4}$ slant columns for each measurement in our window of interest on 17th Jan was selected (the reference measurement was the first to be fitted to establish the zenith reference $\mathrm{O}_{4}$ absorption). Results from this can be seen in Fig. 6. This analysis is more simplistic than other published techniques (e.g. Frieß et al., 2006; Wittrock, 2006) but does provide an initial estimate of aerosol optical depth. The potential uncertainty in the profile shape retrieval is demonstrated by the sudden changes around 9.40 a.m. The use of absolute intensity information, Kalman filters, and optimal estimation techniques would improve this retrieval and are a subject of future work.

The period between 9:15 and 9:50 on 17th January was chosen for particular analysis due to the fine structure in the $\mathrm{NO}_{2}$ differential slant columns. In order to minimise the errors in this fine structure the DOAS retrieval was adapted, with the noon reference spectrum from each individual axis being used as the reference for the spectra from that axis, instead of using the zenith reference for all analysis. This method loses certain information on the vertical profile of the gases, but also removes any influence of the changing instrument line shape over the surface of the CCD (Leigh et al., 2006). Therefore, residuals on all axes were reduced for the 1 min analysis to between $1.3 \%$ for the zenith view and $0.61 \%$ or the 15 degree elevation. Application of this analysis technique also permitted the use of a $2^{\circ}$ viewing angle which was unreliable in the initial analysis owing to its low intensity and differences in instrument line shape compared 


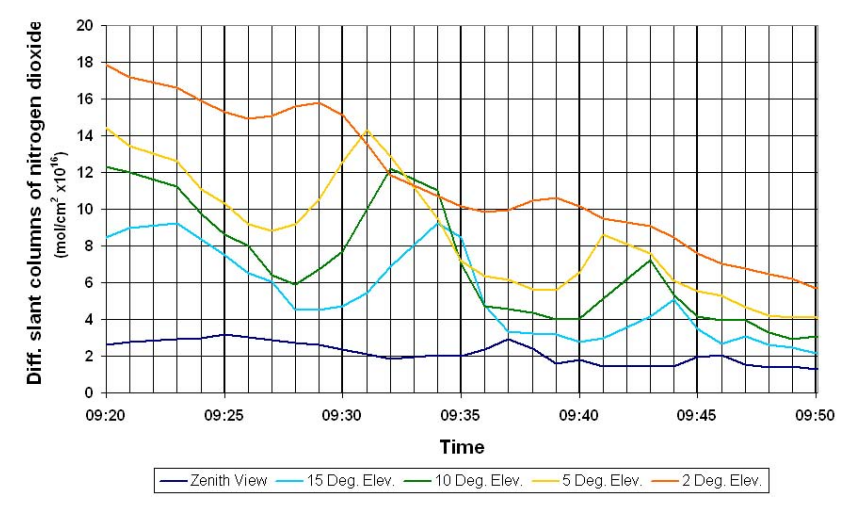

Fig. 7. Passing of two $\mathrm{NO}_{2}$ pollution plumes on the morning of the 17th January 2004

to the zenith view. Detection limits for the zenith, 15, 10, 5 and 2 degree views for this dataset were $0.15,0.31,0.42$, 0.48 and $1.3 \times 10^{16} \mathrm{~mol} / \mathrm{cm}^{2}$ respectively.

Figure 7 shows the morning period between 9.20 and 9.50 a.m. with an expanded time axis. The data in Fig. 7 show distinct peaks indicative of the presence of discrete plumes of $\mathrm{NO}_{2}$ in the viewing direction of the instrument.

The analysis of the finer structure of these peaks provides information on the transport of two plumes, their spatial extent, and their concentration of $\mathrm{NO}_{2}$. The wind speed on the 17th January 2004 was approximately $1.6 \mathrm{~m} \mathrm{~s}^{-1}$ (measurement height: $5 \mathrm{~m}$ ) coming from a northerly direction. As the instrument is placed to the south of the city centre, plumes originating from the city centre are transported sequentially through each viewing direction of the CMAX-DOAS instrument. This progression through the viewing geometries can be clearly seen. Owing to the nature of the recording cycle in the CCD to PC interface, a measurement is missed every 6 to $10 \mathrm{~min}$. In this time period, measurements are missing at 9:22, 9:29, 9:33 and 9:42. The missing measurements at 9:29 and 9:42 are particularly unfortunate in this particular case as they coincide with the two peaks, and cautious interpolations of the peak shapes around these missing points need to be made.

Information on these plumes can be gained from the amplitude of the peaks, their width, and the temporal shift between the appearance in each viewing direction. These parameters are listed in Table 1.

A relatively straightforward geometric analysis can be performed given four assumptions. The first assumption is that the wind speed is constant over the spatial and temporal domain. The wind speed is taken from the Leicester City Council meteorological station, which measures wind speed hourly from the top of a $10 \mathrm{~m}$ mast. The 9 a.m. reading was $1.8 \mathrm{~m} \mathrm{~s}^{-1}$, the 10 a.m. reading was $1.4 \mathrm{~m} \mathrm{~s}^{-1}$. Therefore the assumed wind speed for the period around 9.30 a.m. is $1.6 \mathrm{~m} \mathrm{~s}^{-1}$. No account is made for the increase in windspeed with altitude. This will introduce errors, but does not inval-

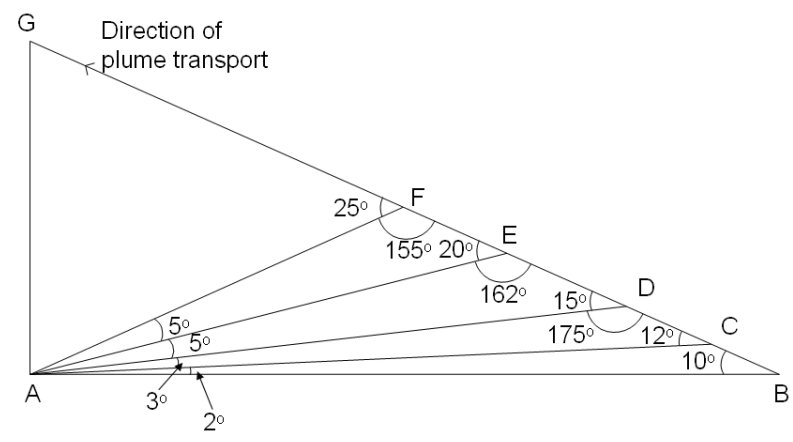

Fig. 8. Simplified geometry for plume analysis (see text).

idate this proof of principle. The second assumption which is necessary is a vertical uplift rate for the plume. In the absence of information required for quantitative calculation of the plume rise rate using the Briggs equations (Briggs, 1975) such as emission speeds and temperatures, a rough estimation of $25 \mathrm{~cm}$ per second, or $10^{\circ}$ in a $1.6 \mathrm{~m} \mathrm{~s}^{-1}$ wind was used. The third assumption is that the plume is spherical in such a slow wind. Such a simplistic assumption will introduce quantification errors, however future instrumental developments involving additional viewing geometries will allow the plume shape to be more accurately assessed. For this first demonstration the mathematical simplicity gained by such simple assumptions is paramount in the absence of significant additional plume shape information.

The final assumption required is that the plume is traveling directly towards the instrument and the centre of the plume is sampled by the off-axis and zenith geometries. Given the instrument position to the south of the city centre, and a measured Northerly wind, this assumption is acceptable within the parameters of this initial analysis.

These assumptions establish a relatively simple triangular geometry of the plume through the viewing angles of the CMAX-DOAS instrument, as illustrated in Fig. 8.

From this geometry several properties of the plume can be estimated. Firstly the dimension of the plume perpendicular to the line of sight from the instrument can be estimated from the time taken for it to be blown through that viewing direction at a given wind speed. This can be expressed as:

$D(\theta)=U \bullet\left(T_{f}(\theta)-T_{s}(\theta)\right)$

where $U=\sqrt{W^{2}+R^{2}}(3)$

$D(\theta)=$ plume diameter when passing through a given viewing angle.

$U=$ plume speed along its line of transport

$T_{S}(\theta)=$ start time of plume measurement from a given viewing angle

$T_{f}(\theta)=$ finish time of plume measurement from a given viewing angle

$W=$ Wind speed as measured by in situ monitors

$R=$ estimated plume rise rate. 


\begin{tabular}{|c|c|c|c|c|c|c|}
\hline \multirow[b]{2}{*}{ Viewing Direction } & \multicolumn{3}{|c|}{ Peak1 } & \multicolumn{3}{|c|}{ Peak2 } \\
\hline & $\begin{array}{c}\text { Amplitude } \\
\left(\mathrm{mol} / \mathrm{cm}^{2}\right) \times 10^{16}\end{array}$ & $\begin{array}{c}\text { Width } \\
\text { (minutes) }\end{array}$ & Time & $\begin{array}{c}\text { Amplitude } \\
\left(\mathrm{mol} / \mathrm{cm}^{2}\right) \times 10^{16}\end{array}$ & $\begin{array}{c}\text { Width } \\
\text { (minutes) }\end{array}$ & Time \\
\hline 2 & 2.2 & 6.5 & $9: 29: 00$ & 1.0 & 4.0 & $9: 38: 30$ \\
\hline 5 & 6.5 & 9.5 & $9: 31: 00$ & 3.0 & 6.6 & $9: 40: 30$ \\
\hline 10 & 7.0 & 8.5 & $9: 32: 00$ & 3.0 & 5.5 & $9: 42: 30$ \\
\hline 15 & 5.5 & 9.0 & $9: 34: 00$ & 2.5 & 5.5 & $9: 44: 00$ \\
\hline Zenith & 1.0 & 4.0 & $9: 37: 00$ & 0.5 & 3.5 & $9: 45: 30$ \\
\hline
\end{tabular}

Table 1. Details of the two pollution peaks shown in Fig. 7

The distance traveled between detection by subsequent viewing geometries can also be estimated through calculation of the distances CD, DE, EF, and FG.

For example

$\mathrm{FE}=\left(T_{p}\left(\theta_{3}\right)-T_{p}\left(\theta_{2}\right)\right) \bullet U$

where:

$\mathrm{FE}$ is the distance between points $\mathrm{F}$ and $\mathrm{E}$ in Fig. 8.

$T_{p}\left(\theta_{3}\right)=$ is the time of peak plume intensity from viewing angle 3 .

Once the distance FE has been calculated, the triangle AFE can be solved, calculating distances to the plume centres when the peak concentrations are being measured.

$\mathrm{AF}=\frac{\sin \left(5^{\circ} \bullet \mathrm{FE}\right)}{\sin \left(155^{\circ}\right)}$

Using the elevation angles of each viewing geometry and the calculated distance of the plume from the instrument, the horizontal $\left(\mathrm{H}^{\mathrm{AF}}\right)$ and vertical $\left(\mathrm{V}^{\mathrm{AF}}\right)$ displacement of the centre of the plume can be calculated at the time $T_{p}\left(\theta_{3}\right)$.

$$
\begin{aligned}
& \mathrm{V}^{\mathrm{AF}}=\sin \left(15^{\circ}\right) \bullet \mathrm{AF}(6) \\
& \mathrm{H}^{\mathrm{AF}}=\cos \left(15^{\circ}\right) \bullet \mathrm{AF}(7)
\end{aligned}
$$

The maximum absorption of the plume can be measured from the amplitude of the plume peak above the background $\mathrm{NO}_{2}$ concentration. Given the assumption that most photons are scattered behind the plume, the absorption path length through the plume can be initially estimated using an assumed spherical plume shape where the absorption path is equal to the measured plume diameter $D(\theta)$. The average concentration in $\mathrm{mol} \mathrm{cm} \mathrm{cm}^{-3}$ within the plume can be calculated from:

$N_{\theta}=\frac{A_{\theta}}{D(\theta)}$

where $\mathrm{A}_{\theta}$ is the amplitude of the peak as measured by a the view geometry with elevation angle $\theta\left(\mathrm{mol} \mathrm{cm}{ }^{-2}\right)$.

The results of these calculations therefore provide estimations of the size of the plume, its position, and its concentration. Even with the assumption of spherical plumes, a first approximation of plume concentrations can be derived. However, the weakness of the assumption is evident as the plume concentration is calculated to decrease significantly as the plume is measured by the zenith view. This is chemically inconsistent with existing knowledge of urban $\mathrm{NO}_{2}$ chemistry, and a much more likely scenario is a shallower, flatter plume which for a given concentration would cause a smaller amount of absorption in the vertical plane than the horizontal. The possibility that the zenith view is only measuring the edge of the plume must also be considered. The assumption that at each stage we are measuring the centre of the plume is a considerable one, especially as the calculated distance between the $15^{\circ}$ measurement and the zenith measurement is 600 to $800 \mathrm{~m}$. It is very likely that to some degree the zenith measurements for both plumes are lower due to the plume being blown through the off-axis viewing geometries and then to the side of the instrument rather than directly overhead. Without the use of additional azimuthal geometries it is difficult to quantify the extent of this effect.

Adjusting the assumption of spherical plumes to allow for a more elliptical geometry permits a more realistic modeling of likely plume dimensions. Using an assumed eccentricity, the path length through a plume with an elliptical cross section can be determined and used in concentration calculations. The path length through the plume from a given viewing geometry is dependent upon the elevation angle of that geometry and the eccentricity of the ellipse. The eccentricity of the ellipse is defined as:

$\varepsilon=\sqrt{1-\left(\frac{Y}{X}\right)^{2}}$

With wind fields of $1.6 \mathrm{~m} \mathrm{~s}^{-1}$ horizontally, and $0.25 \mathrm{~m} \mathrm{~s}^{-1}$ vertically, an Y/X value of 0.2 was used as an initial estimation of plume shape. An intermediate step using Y/X of 0.4 was also calculated to provide a measure of the sensitivity of calculated concentrations to this Y/X factor. Results from these calculations, including estimated plume positions, dimensions and concentrations at each of the 5 points at which the plume is sampled, are shown in Fig. 9. The rapid increase in derived concentration in the zenith view in the second panel of Fig. 9 is indicative of the potential errors in the assumption of a Y/X value of 0.2 in this case. The vertical path through such a flattened plume is relatively small, therefore an unrealistically high concentration is derived. The $\mathrm{Y} / \mathrm{X}$ value of 0.4 produces more realistic plume scenarios, 
however further conclusions are under constrained without additional sampling paths through the plume and additional information on the wind vectors and plume rise rate.

\subsection{Source indications and strength estimation}

The total mass of $\mathrm{NO}_{2}$ in the plumes can be roughly estimated through calculation of the volume of the elliptical plumes. If the assumption is made that the concentration is constant throughout the plume, and that the elliptical plume has the same dimensions in the vertical and East-West dimension, then the total mass of $\mathrm{NO}_{2}$ within the plume can be calculated for any of the ellipses drawn in Fig. 9.

For example, for plume 1 (see Table 1) measured by the $15^{\circ}$ elevation angle, using an assumed $\mathrm{Y} / \mathrm{X}$ factor of 0.2 , the measured diameter is $877 \mathrm{~m}$, and the concentration is $26 \mathrm{ppb}$. Therefore the total mass of $\mathrm{NO}_{2}$ in that plume, given the above assumptions can be calculated as follows:

Total Volume $=\frac{4}{3} \pi \times(877 \times 0.5) \times(877 \times 0.4 \times 0.5) \times$ $(877 \times 0.4 \times 0.5)=1.46 \times 10^{7} \mathrm{~m}^{3}$

$1 \mathrm{ppb}=1.913 \mu \mathrm{g} \mathrm{m}^{-3}$

$26 \mathrm{ppb}=49.738 \mu \mathrm{g} \mathrm{m}^{-3}=4.974 \times 10^{-8} \mathrm{~kg} \mathrm{~m}^{-3}$.

Therefore the total mass of $\mathrm{NO}_{2}$ in the plume $=4.974 \times$ $10^{-8} \times 1.46 \times 10^{7}=0.73 \mathrm{~kg}$.

This is a significant mass of $\mathrm{NO}_{2}$, which would require a repeated and distinct emission source. The estimated source position can be estimated by extrapolating back from the measured plume positions from the different axes and calculating the distance $\mathrm{AB}$ in Fig. 8. For both plumes the source location is calculated to be between 1.2 and $1.4 \mathrm{~km}$ to the north of the CMAX-DOAS instrument. The main train station in Leicester is located approximately $1.3 \mathrm{~km}$ to the north of the site of the CMAX-DOAS instrument. The acceleration of diesel trains out of the station is therefore a possible source of such significant plumes.

As a further demonstration of capability, two additional viewing geometries were temporarily added to the CMAX DOAS instrument on 11th November 2004. These geometries were at $15^{\circ}$ elevation angle, with one telescope pointing at $20^{\circ}$ and the other at $340^{\circ}+/-2^{\circ}$ azimuthal angles (i.e. one telescope $20^{\circ}$ east of the permanent view geometries, and one $20^{\circ}$ west). These additional viewing geometries permitted the tracking of individual plumes as they were blown by a westerly wind through the different viewing geometries.

The use of 7 concurrent fibres necessitated the concentration of the images on the CCD chip. Normal operation with 5 fibres used alternate inputs into the 9-way multi-track fibre giving a spacing between images of approximately 100 rows, and negligible stray-light concerns. This configuration therefore not only tested the utility of the additional viewing geometries, but also the capability of the CCD and spectrometer system to accommodate additional viewing geometries.

Clear sky conditions were available during the morning period around 8 a.m., when the wind direction was approximately $210^{\circ}$ with an average wind speed of $1.5 \mathrm{~m} \mathrm{~s}^{-1}$.
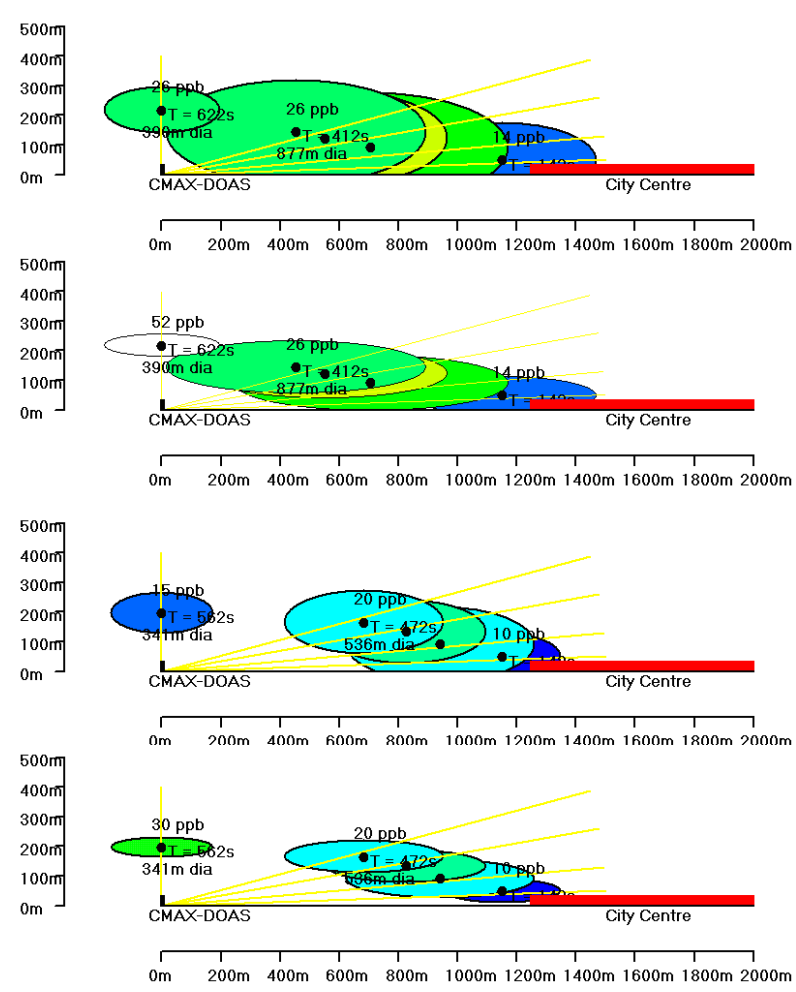

Fig. 9. Calculation of the positions and concentrations for plumes on 17th January 2004 (see Fig. 7) (plume 1 upper 2 panels, plume 2 lower two panels) using a Y/X ratio of 0.4 (top) and 0.2 (bottom).

Therefore, plumes detected around this time would be traveling from the South West to the North East at approximately $1.5 \mathrm{~m} \mathrm{~s}^{-1}$. Slant columns of $\mathrm{NO}_{2}$ from the available azimuthal angles are shown in Fig. 10. Reference spectra from each viewing angle were used, rather than using a single zenith reference spectrum. Three pollution peaks were observed between 7 and 9 a.m.. Three plumes can be seen to progress through the Westerly view, the northerly-viewing geometries, and finally the most Easterly telescope. $\mathrm{O}_{4}$ slant columns for the same period are shown in Fig. 11 demonstrating that although there is some structure, suggesting a little cloud cover on this particular morning, there are not the three distinct structures observed in the $\mathrm{NO}_{2}$ data.

The irregular shapes of these three plumes render the analysis problematic given such minimal constraining data points. Initial information is available from the plume amplitudes, which are approximately $2 \times 10^{16} \mathrm{~mol} \mathrm{~cm}^{-2}$, therefore these plumes are less concentrated than plume 1 in Fig. 7 from 17th January 2004. With a wind speed of $1.5 \mathrm{~m} \mathrm{~s}^{-1}$ at $210^{\circ}$ the components of the wind speed in the South-North, and West-East directions are 1.3 and $0.75 \mathrm{~m} \mathrm{~s}^{-1}$ respectively. Transit times of 4-6 min through the viewing geometries give an initial estimation of diameter of $720 \mathrm{~m}$. Gaps of approximately $1 \mathrm{~min}$ between peak detection in the azimuthal directions for all 3 peaks gives an estimated distance from the 


\begin{tabular}{|c|c|c|c|}
\hline & $\begin{array}{l}\text { Differential } \\
\text { Slant Columns }\end{array}$ & $\begin{array}{l}\text { Volume Mixing } \\
\text { Ratios }\end{array}$ & $\begin{array}{l}\text { Plume } \\
\text { Reconstruction }\end{array}$ \\
\hline $\begin{array}{l}\text { Major } \\
\text { contributory } \\
\text { errors }\end{array}$ & $\begin{array}{l}\text { Instrument line } \\
\text { shape, wavelength } \\
\text { calibration, CCD } \\
\text { readout noise }\end{array}$ & $\begin{array}{l}\text { Assumptions from } \\
\text { Sect. } 3.1 \\
\text { particularly } \\
\text { assumptions } 3 \text { and } 4 \\
\text { Absolute: }+33 \%,-66 \%\end{array}$ & $\begin{array}{l}\text { plume dimensions, } \\
\text { wind vectors } \\
\text { plume rise rate assumptions } \\
\text { unconstrained plume dimensions }\end{array}$ \\
\hline $\begin{array}{l}\text { Error } \\
\text { estimate }\end{array}$ & $\begin{array}{l}\text { single fibre }-2 \% \\
\text { multi fibre } 5 \% \\
\text { (Leigh et al., 2006; Leigh, 2006) }\end{array}$ & $\begin{array}{l}\text { Based on PBL height variability } \\
\text { Trends: Optimal } 15 \%\left(5 \mu \mathrm{g} \mathrm{m}^{-3}\right) \\
\text { Normal } 34 \%\left(10.9 \mu \mathrm{g} \mathrm{m}^{-3}\right) \\
\text { Based on in situ comparisons }\end{array}$ & $\begin{array}{l}\text { lower boundary }-50 \% \\
\text { upper boundary - unconstrained }\end{array}$ \\
\hline $\begin{array}{l}\text { Detection } \\
\text { limit }\end{array}$ & $\begin{array}{l}\text { single fibre }-1.4 \times 10^{15} \mathrm{~mol} \mathrm{~cm}^{-2} \\
5 \text { degree view }-4.7 \times 10^{15} \mathrm{~mol} \mathrm{~cm}^{-2}\end{array}$ & $1.5 \mu \mathrm{g} \mathrm{m}^{-3}$ & $\begin{array}{l}\text { Dependent upon } \\
\text { plume geometry }\end{array}$ \\
\hline
\end{tabular}

Table 2. Estimated and calculated errors for the three analysis modes of this instrument.

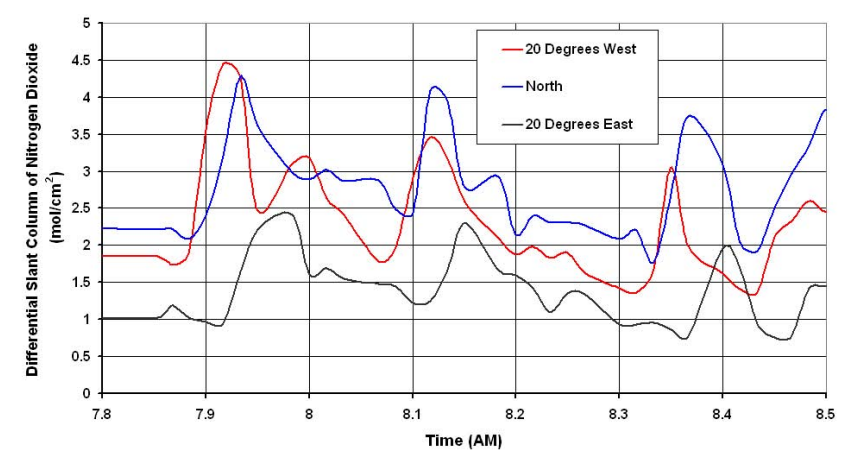

Fig. 10. Differential slant columns of $\mathrm{NO}_{2}$ from the three telescopes at 15 elevation on 11th November 2004, showing the progression of three individual plumes as they progress from West to East.

instrument of approximately $(60 \times 0.75) / \tan 20=125 \mathrm{~m}$. With the incorporation of additional viewing geometries or an increase in temporal resolution, more information on plume dimensions and concentrations could be gained.

A summary of the performance of this technique is given in Table 2. Errors increase significantly with the assumptions required to obtain a single volume mixing ratio, or scenario for plume reconstruction. Best estimates are given for errors where established error calculations are not appropriate or available. Errors for the volume mixing ratio are taken from the degree of agreement with the in situ monitor, while errors on the plume analysis are estimated from the degree of possible divergence from the assumed state. As such the lower boundary is taken as $50 \%$ owing to the possibility that plume shape could be extended in the direction of the absorption path through it, giving an enhanced reading. The lack of measurements in the azimuth direction, or along the absorption path (from an instrument placed perpendicular to the CMAX-DOAS for example) results in no constraint on the maximum possible size of the plume.

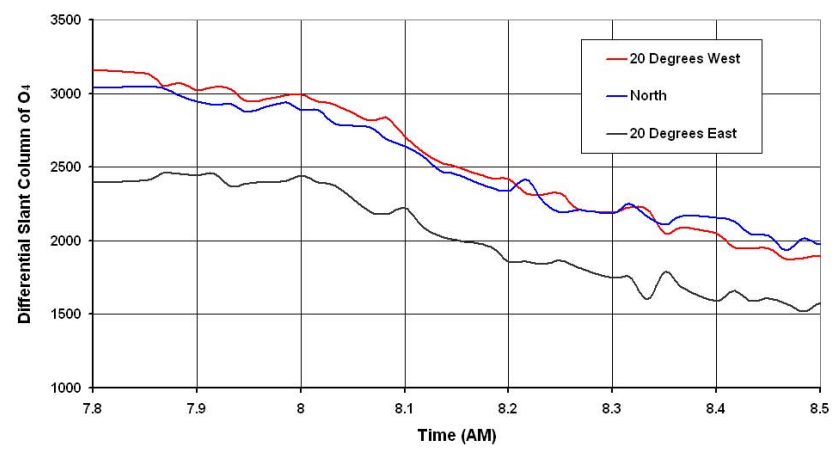

Fig. 11. Differential slant columns of $\mathrm{O}_{4}$ for the morning of 11th November 2004, showing predominantly clear sky conditions.

\section{Conclusions}

Sensitivity tests have demonstrated the reliability of fine structure visible in slant columns measured in urban environments with the CMAX-DOAS instrument. (Leigh et al., 2006) This work has shown through the use of some simple assumptions and radiative transfer modelling, the ability to retrieve information on trace gas concentrations in an urban atmosphere. Such tropospheric measurements provide a measure of the integrated concentration of the trace species along a path above the city centre. These measurements therefore provide a useful measure of overall trace gas concentrations on a city-wide scale. These measurements are have been shown to be comparable to a chemiluminescence monitor placed in a sheltered location in the city centre within a margin of 15 to $40 \%$ ( 5 to $11 \mu \mathrm{g} \mathrm{m}^{-3}$ ) depending on instrumental and wind conditions. Such agreement confirms the ability of both instruments to retrieve reliable measurements of $\mathrm{NO}_{2}$ concentrations over a moderately-sized urban area with a multitude of individual sources. By analysing the fine structure of CMAX-DOAS measurements, individual plumes of $\mathrm{NO}_{2}$ can be identified as they are blown through 
the instrument viewing geometries. The concurrent nature of the measurements from the CMAX-DOAS instrument enables limited spatial information to be derived from peaks which are visible in multiple axes.

In favourable wind conditions, in which the original source of the plume is directly downwind of the instrument, a simplified geometry can be used to reconstruct plume dimensions, concentrations and source location. This simplified geometry makes numerous assumptions owing to the very limited spatial information available. However, despite the significant assumption uncertainties, derived plume dimensions and concentrations are within expected parameters and likely source locations can be identified.

The CCD and imaging spectrometer system demonstrated in this work is capable of accommodating up to a total of 20 viewing geometries, with minimal stray light problems caused by a 50-row separation between imaged spectra. Additional azimuthal telescopes could be used to track the spatial extent and transit of plumes in all wind conditions. With only 2 additional azimuthal telescopes, the amount of spatial information is very limited. However, the irregular plume shapes expected, and suggested by initial investigations demonstrate the utility of each additional view. With the development of the next generation of instrument incorporating 20 fixed telescopes the amount of spatial and temporal information available increases significantly. Using two or more instruments with intersecting viewing geometries would constrain the depth dimension of analysed plumes. The extension of techniques demonstrated in this work into multiple instruments with intersecting viewing geometries can be seen as a way of imaging city-scale import, emission and export.

Acknowledgements. The authors would like to thank Leicester City Council for provision of wind field and chemiluminescence data. We are also grateful to NERC for funding this project under contract NER/S/A/06294.

Edited by: R. Cohen

\section{References}

Aliwell, S. R., Van Roozendael, M., Johnston, P. V., Richter, A., Wagner, T., Arlander, D. W., Burrows, J. P., Fish, D. J., Jones, R. L., Tornkvist, K. K., Lambert, J. C., Pfeilsticker, K., and Pundt, I.: Analysis for $\mathrm{BrO}$ in zenith-sky spectra: An intercomparison exercise for analysis improvement, J. Geophys. Res.Atmos., 107, 4199, 2002.

Bobrowski, N., Hönninger, G., Galle, B., and Platt, U.: Detection of bromine monoxide in a volcanic plume, Nature, 423, 273-276, 2003.

Briggs, G.: Plume rise predictions, lectures on Air Pollution and Environmental Impact Analysis, Tech. rep., U.S. Dept of Energy, 1975.
Eresmaa, N., Karppinen, A., Joffre, S. M., Rsnen, J., and Talvitie, H.: Mixing height determination by ceilometer, Atmos. Chem. Phys., 6, 1485-1493, 2006, http://www.atmos-chem-phys.net/6/1485/2006/.

Frieß, U., Wagner, T., Pundt, I., Pfeilsticker, K., and Platt, U.: Spectroscopic measurements of tropospheric iodine oxide at Neumayer Station, Antarctica, Geophys. Res. Lett., 28, 1941-1944, 2001.

Frieß, U., Monks, P. S., Remedios, J. J., Rozanov, A., Sinreich, R., Wagner, T., and Platt, U.: MAX-DOAS $\mathrm{O}_{4}$ measurements: A new technique to derive information on atmospheric aerosols: 2. Modelling studies, J. Geophys. Res.-Atmos., 111, D14203, doi:10.1029/2005JD006618, 2006.

Heckel, A., Richter, A., Tarsu, T., Wittrock, F., Hak, C., Pundt, I., Junkermann, W., and Burrows, J. P.: MAX-DOAS measurements of formaldehyde in the Po-Valley, Atmos. Chem. Phys., 5, 909 918, 2005.

Hönninger, G., Bobrowski, N., Palenque, E. R., Torrez, R., and Platt, U.: Reactive bromine and sulfur emissions at Salar de Uyuni, Bolivia, Geophys. Res. Lett., 31, L04101, 2004a.

Hönninger, G., Leser, H., Sebastian, O., and Platt, U.: Groundbased measurements of halogen oxides at the Hudson Bay by active longpath DOAS and passive MAX-DOAS, Geophys. Res. Lett., 31, L04111, 2004b.

Hönninger, G., von Friedeburg, C., and Platt, U.: Multi axis differential optical absorption spectroscopy (MAX- DOAS), Atmos. Chem. Phys., 4, 231-254, 2004c.

Johnston, P. V. and McKenzie, R. L.: NO2 Observations at 45Degrees-S During the Decreasing Phase of Solar-Cycle 21, from 1980 to 1987, J. Geophys. Res.-Atmos., 94, 3473-3486, 1989.

Leigh, R. J.: A Concurrent Multi-Axis Differential Optical Absorption Spectroscopy system for the Measurement of Tropospheric Nitrogen., Ph.D. thesis, University of Leicester, http://www.leos.le.ac.uk/publications/pdfs/theses/RJL PhDThesis_2006.pdf, 2006.

Leigh, R. J., Corlett, G. K., Frieß, U., and Monks, P. S.: A Concurrent Multi-Axis Differential Optical Absorption Spectroscopy system for the Measurement of Tropospheric Nitrogen Dioxide., Appl. Opt., 45, 7504-7518, 2006.

Leser, H., Hönninger, G., and Platt, U.: MAX-DOAS measurements of $\mathrm{BrO}$ and $\mathrm{NO}_{2}$ in the marine boundary layer, Geophys. Res. Lett., 30, 1537, 2003.

Menut, L., Flamant, C., Pelon, J., and Flamant, P. H.: Urban Boundary-Layer Height Determination from Lidar Measurements Over the Paris Area, Appl. Optics, 38, 945-954, 1999.

Miller, H. L., Weaver, A., Sanders, R. W., Arpag, K., and Solomon, S.: Measurements of arctic sunrise surface ozone depletion events at Kangerlussuaq, Greenland (67 degrees N, to 51 degrees W), Tellus B, 49, 496-509, 1997.

Noxon, J. F.: Nitrogen Dioxide in the Stratosphere and Troposphere measured by Ground-based absorption spectroscopy., Science, 189, 547-549, 1975.

Noxon, J. F., Whipple, E. C., and Hyde, R. S.: Stratospheric $\mathrm{NO}_{2}$, 1. Observational method and behaviour at Midlatitudes., J. Geophys. Res.-Atmos., 84, 5047-5076, 1979.

Platt, U.: Differential optical absorption spectroscopy, (DOAS), in air monitoring by spectroscopic techniques., in: Chemical Analysis, edited by: M. W., Sigrist, 127, Wiley, New York, 1994.

Rozanov, A., Rozanov, V., and Burrows, J.: Combined differential- 
integral approach for the radiation field computation in a spherical shell atmosphere: Nonlimb geometry, J. Geophys. Res., 105, 937, 2000.

Rozanov, A., Rozanov, V., and Burrows, J. P.: A numerical radiative transfer model for a spherical planetary atmosphere: combined differential-integral approach involving the Picard iterative approximation, J. Quantitative Spectroscopy and Radiative Transfer, 69, 491-512, 2001.

Sanders, R. W.: Improved analysis of atmospheric absorption spectra by including the temperature dependence of $\mathrm{NO}_{2}$, J. Geophys. Res.-Atmos., 101, 20 945-20 952, 1996.

Sinreich, R., Volkamer, R., Filsinger, F., Frieß, U., Kern, C., Platt, U., Sebastián, O., and Wagner, T.: MAX-DOAS detection of glyoxal during ICARTT 2004, Atmos. Chem. Phys., 6, 9459-9481, 2006.

Solomon, S., Schmeltekopf, A. L., and Sanders, R. W.: On the Interpretation of Zenith Sky Absorption-Measurements, J. Geophys. Res.-Atmos., 92, 8311-8319, 1987.

Stutz, J. and Platt, U.: Numerical analysis and estimation of the statistical error of differential optical absorption spectroscopy measurements with least-squares methods, Appl. Optics, 35, 60416053, 1996.

Tornkvist, K. K., Arlander, D. W., and Sinnhuber, B. M.: Groundbased UV measurements of $\mathrm{BrO}$ and $\mathrm{OClO}$ over $\mathrm{Ny}$-Alesund during winter 1996 and 1997 and Andoya during winter 1998/99, J. Atmos. Chem., 43, 75-106, 2002.
Van Roozendael, M., Hermans, C., Demaziere, M., and Simon, P. C.: Stratospheric $\mathrm{NO}_{2}$ observations at the Jungfraujoch Station between June 1990 and May 1992, Geophys. Res. Lett., 21, 1383-1386, 1994.

Wagner, T., Dix, B., von Friedeburg, C., Friess, U., Sanghavi, S., Sinreich, R., and Platt, U.: MAX-DOAS $\mathrm{O}_{4}$ measurements: A new technique to derive information on atmospheric aerosols - Principles and information content, J. Geophys. Res.-Atmos., 109, doi:10.1029/2004JD004904, D22205, 2004.

Wittrock, F.: The retrieval of oxygenated volatile organic compounds by remote sensing techniques., Ph.D. thesis, University of Bremen, Germany, 2006.

Wittrock, F., Muller, R., Richter, A., Bovensmann, H., and Burrows, J. P.: Measurements of iodine monoxide (IO) above Spitsbergen, Geophys. Res. Lett., 27, 1471-1474, 2000.

Wittrock, F., Oetjen, H., Richter, A., Fietkau, S., Medeke, T., Rozanov, A., and Burrows, J. P.: MAX-DOAS measurements of atmospheric trace gases in Ny-Alesund - Radiative transfer studies and their application, Atmos. Chem. Phys., 4, 955-966, 2004. 